\title{
Plasma alkaline phosphatase activity in rickets of prematurity
}

\author{
E J GLASS, R HUME, G M A HENDRY, R C STRANGE, AND J O FORFAR \\ Department of Child Life and Health, University of Edinburgh, and \\ Simpson Memorial Maternity Pavilion, Royal Infirmary, Edinburgh
}

SUMMARY Plasma alkaline phosphatase activity was measured in 349 infants aged between 5 and 10 days to establish a normal range for different gestational ages. Significant differences were observed between term and preterm infants, the highest values being associated with the shortest lengths of gestation. Plasma calcium, phosphate, and alkaline phosphatase activity were measured sequentially in 51 preterm infants $<1500 \mathrm{~g}$ at birth. A significant correlation was found between raised plasma alkaline phosphatase activity and radiological changes of osteoporosis, metaphyseal change, and periosteal reaction. Plasma alkaline phosphatase appears to be of value in screening for and monitoring rickets of prematurity.

The predisposition of the preterm infant to rickets has been known for many years, ${ }^{1}$ and is being increasingly found among extremely low birthweight infants. $^{2-5}$ The early detection and treatment of rickets may have important implications for linear growth of the preterm infant. ${ }^{6}$ Florid changes in the $x$-ray film occur late in the disease and although photonabsorptiometry ${ }^{7}$ can detect early demineralisation, the technique is not widely available. We report the value of plasma alkaline phosphatase activity as a sensitive and early indicator of rickets of prematurity.

\section{Patients and methods}

To establish a normal range for infants of differing gestational ages, plasma alkaline phosphatase activity was measured in 349 infants aged between 5 and 10 days. This timing was chosen as after parturition the placental isoenzyme disappears from plasma with a half-life of 3 or 4 days. ${ }^{8}$ The gestational age of these infants ranged from 26 to 40 weeks. Plasma alkaline phosphatase was measured by the method of Morgenstern et al. ${ }^{9}$

Fifty-one preterm infants weighing less than $1500 \mathrm{~g}$ at birth who were admitted to the regional intensive care unit during the period October 1978 to October 1980 were studied sequentially. Feeding was by the enteral or parenteral route. Plasma calcium, phosphate, and alkaline phosphatase levels were measured weekly during their stay in hospital, and subsequently at 2-4 weekly intervals as outpatients until the alkaline phosphatase activity was below $500 \mathrm{U} / 1$. Plasma alkaline phosphatase activity greater than $500 \mathrm{U} / 1$ was taken as an indication that isoenzyme studies were necessary. ${ }^{8}$

Radiological examination was not performed routinely, but 42 babies had $x$-ray films taken on clinical indication. On completion of the study all $x$-ray films were assessed independently of clinical and biochemical data by a paediatric radiologist. Generally chest $x$-ray films were analysed, but many infants had abdominal $x$-rays which included the spine and pelvis on the film, while $x$-ray films of the skull and wrist were examined if available. The radiographic features analysed were bone mineralisation, the presence or absence of metaphyseal changes, and periosteal reaction. The degree of bone demineralisation was arbitrarily graded 1-3 according to severity. Osteoporosis was detected most readily in the ribs and scapulae. Metaphyseal changes; cupping, fraying, and expansion were noted in the humeri. The biochemical and radiological data were correlated statistically by Kendall's rank correlation for osteoporosis, by Wilcoxon's rank sum for metaphyseal change, and by Fisher's exact test for periosteal reaction.

During the study 400 IU of vitamin D2 a day were given to enterally-fed infants, and $100 \mathrm{IU} / \mathrm{kg}$ a day intravenously to parenterally-fed infants. If the plasma alkaline phosphatase activity exceeded $500 \mathrm{U} / 1$, the vitamin D2 supplement was increased to 1000 IU a day. At values above $1000 \mathrm{U} / 1$ vitamin D2 was replaced by an oral preparation of $1, \alpha-$ 
hydroxycholecalciferol (1 alpha) $0.05 \mu \mathrm{g} / \mathrm{kg}$ a day. In the event of failure to respond to the latter 1,25dihydroxycholecalciferol (Rocaltrol) was prescribed in a dosage of $0.05 \mu \mathrm{g} / \mathrm{kg}$ a day.

\section{Results}

The variation in plasma alkaline phosphatase activity in relation to gestational age at birth in 349 infants is shown in Table 1. Significant differences (Student's $t$ test) in plasma alkaline phosphatase activity were observed between term and preterm infants.

The 51 infants studied sequentially were divided into 4 groups according to their maximum plasma alkaline phosphatase activity during the period of the study (Table 2). In patients with plasma alkaline phosphatase values greater than $500 \mathrm{U} / 1(71 \%)$, including infants with cholestasis, the predominant isoenzyme was of bone origin. The groups of infants with higher plasma alkaline phosphatase values (groups 3 and 4) were of lower mean birthweight and gestation, and had longer periods of parenteral nutrition than infants with lower peak alkaline phosphatase values (groups 1 and 2). No significant differences were noted in plasma phosphate levels, and plasma calcium was significantly lower only in the most severely affected infants (group 4).

In infants developing radiological rickets the highest and most sustained maximal plasma alkaline phosphatase values occurred in the more severe cases. However, the maximal value and the period of increased plasma alkaline phosphatase values were modified by treatment. Of 7 infants with peak alkaline phosphatase values greater than $1000 \mathrm{U} / 1$ treated with $1, \alpha$-hydroxycholecalciferol (mean duration 13 days), 6 showed a satisfactory response with a decline in plasma alkaline phosphatase activity from a mean value of $1221 \mathrm{U} / 1 \pm 125$ (before treatment) to $751 \mathrm{U} / 1 \pm 83 \cdot 3$ (after treatment). In the 7 th infant,

Table 1 Plasma alkaline phosphatase variations in relation to gestational age

\begin{tabular}{|c|c|c|c|c|c|c|c|c|c|}
\hline \multirow{2}{*}{$\begin{array}{l}\text { Alkaline phosphatase } \\
\text { activity } \\
(U / l)\end{array}$} & \multirow{2}{*}{$\begin{array}{l}\text { Number } \\
\text { in } \\
\text { group }\end{array}$} & \multirow{2}{*}{$\begin{array}{l}\text { Gestation } \\
\text { (weeks) }\end{array}$} & \multicolumn{7}{|c|}{ Gestation (weeks) } \\
\hline & & & $26+27$ & $28+29$ & $30+31$ & $32+33$ & $34+35$ & 36 & Term \\
\hline $\begin{array}{l}319 \cdot 54 \pm 142 \cdot 31 \\
291 \cdot 81 \pm 86 \cdot 49 \\
281 \cdot 15 \pm 84 \cdot 49 \\
253 \cdot 98 \pm 71 \cdot 85 \\
236 \cdot 30 \pm 61 \cdot 78 \\
207 \cdot 16 \pm 59 \cdot 52 \\
164 \cdot 1 \pm 67 \cdot 8\end{array}$ & $\begin{array}{r}13 \\
26 \\
46 \\
53 \\
103 \\
48 \\
60 \\
349\end{array}$ & $\begin{array}{l}26+27 \\
28+29 \\
30+31 \\
32+33 \\
34+35 \\
36 \\
38-41\end{array}$ & & NS & $\begin{array}{l}\text { NS } \\
\text { NS }\end{array}$ & $\begin{array}{l}<0.02 \\
\text { NS } \\
\text { NS }\end{array}$ & $\begin{array}{l}<0.001 \\
<0.001 \\
<0.001 \\
\text { NS }\end{array}$ & $\begin{array}{l}<0.001 \\
<0.001 \\
<0.001 \\
<0.001 \\
<0.01\end{array}$ & $\begin{array}{l}<0.001 \\
<0.001 \\
<0.001 \\
<0.001 \\
<0.001 \\
<0.001\end{array}$ \\
\hline
\end{tabular}

Alkaline phosphatase activity expressed as mean $\pm 1 \mathrm{SD}$.

Table 2 Classification of 51 preterm $<1500 \mathrm{~g}$ infants according to maximum plasma alkaline phosphatase activity

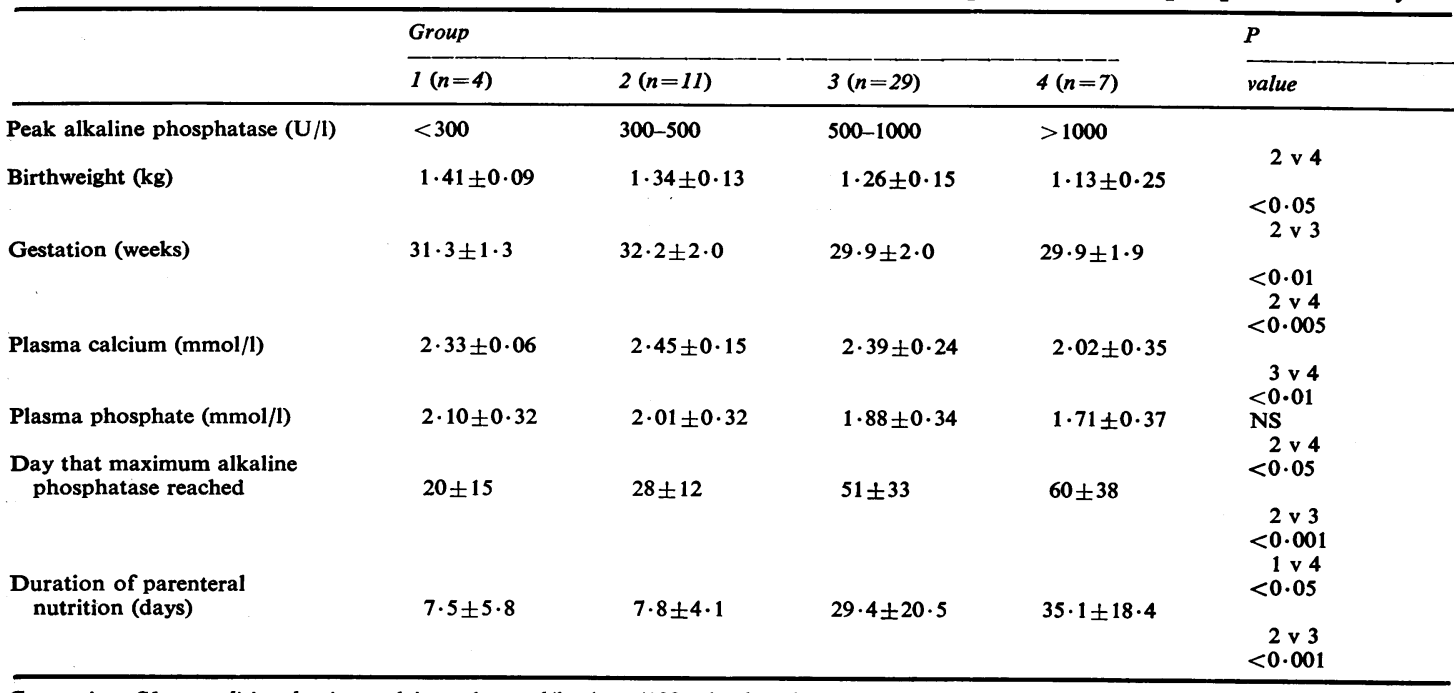

Conversion: SI to traditional units-calcium: $1 \mathrm{mmol} / 1 \approx 4 \mathrm{mg} / 100 \mathrm{ml}$; phosphate $1 \mathrm{mmol} / 1 \approx 3 \cdot 1 \mathrm{mg} / 100 \mathrm{ml}$. 
Table 3 Correlations between plasma alkaline phosphatase and radiological bone changes in preterm low birthweight $(<1500 \mathrm{~g})$ infants

\begin{tabular}{|c|c|c|c|c|c|}
\hline Peak alkaline phosphatase $(U / I)$ & $\begin{array}{c}<300 \\
(n=4)\end{array}$ & $\begin{array}{l}300-500 \\
(n=11)\end{array}$ & $\begin{array}{l}500-1000 \\
(n=29)\end{array}$ & $\begin{array}{l}>1000 \\
(n=7)\end{array}$ & $P$ value \\
\hline \multicolumn{6}{|l|}{ Mineralisation } \\
\hline Normal mineralisation & 2 & 8 & 1 & 0 & \\
\hline ?Osteoporosis/normal & 1 & 1 & 1 & 0 & \\
\hline \multicolumn{6}{|l|}{ Osteoporosis } \\
\hline Grade 1 & 0 & 1 & 7 & 0 & \\
\hline Grade 2 & 0 & 0 & 10 & 4 & $<0.001$ \\
\hline Metaphyseal change & 0 & 0 & 4 & 4 & $<0.01$ \\
\hline Periosteal reaction & 0 & 0 & 0 & 2 & $<0.024$ \\
\hline No $x$-ray film & 1 & 1 & 7 & 0 & \\
\hline
\end{tabular}

who had appreciable cholestasis, the plasma alkaline phosphatase activity continued to rise despite $1, \alpha$-hydroxycholecalciferol. After 21 days of treatment with 1,25-dihydroxycholecalciferol, the plasma alkaline phosphatase activity declined from 1940 to $995 \mathrm{U} / 1$.

Correlation between biochemical and radiological findings are shown in Table 3. The degree of osteoporosis, presence of metaphyseal changes, and periosteal reaction were all significantly related to maximum alkaline phosphatase activity. All patients with metaphyseal changes had maximum alkaline phosphatase activity greater than $750 \mathrm{U} / \mathrm{l}$. Periosteal reactions were seen only if alkaline phosphatase activity exceeded $1000 \mathrm{U} / 1$. All infants with abnormal wrist $x$-ray films had changes in the humeri. Maximal peak alkaline phosphatase activity generally preceded maximum radiological change by 2 to 4 weeks.

\section{Discussion}

Variations in plasma alkaline phosphatase activity with gestational age were found in a group of 349 infants aged between 5 and 10 days, with a downwards trend between 26 and 40 weeks' gestation. Significant differences were noted between term and preterm infants $(P<0.001)$. This variation may reflect the measurement of different alkaline phosphatase isoenzyme activities at different gestational ages.

In the 51 infants studied sequentially, the radiological changes of osteoporosis, metaphyseal change, and periosteal reaction were all significantly related to peak alkaline phosphatase activity.

The classical changes which occur in children with rickets have been well described. ${ }^{10}$ The main features are rarefaction, cupping, and fraying of the metaphyses together with loss of the provisional zone of calcification. Periosteal reactions and fractures through demineralised bone may occur. In preterm infants a diffuse demineralisation of the skeleton particularly affecting the ribs, spine, skull, and scapula often with super added fractures has been noted. ${ }^{11} 12$ In the infants studied radiological changes of osteoporosis correlated with biochemical evidence of rickets. In contrast Eek et al ${ }^{13}$ regarded diffuse osteoporosis, resolving without treatment as a normal phenomenon in the preterm infant. Periosteal reaction has been described in preterm infants during both active ${ }^{3}$ and healing ${ }^{10}$ rickets. However Malmberg $^{14}$ described periosteal reaction unassociated with rickets in preterm infants. Periosteal reactions were noted in only 2 of our patients, both of whom had peak alkaline phosphatase levels in excess of $1000 \mathrm{U} / 1$.

Plasma calcium and phosphate values did not appear to be good indicators of rickets in these infants. Plasma calcium fell significantly only in the most severely affected group, and no significant differences were noted in plasma phosphate values. Plasma calcium values are likely to be particularly misleading in parenterally-fed infants.

Inadequate calcium input is one of the factors implicated in the aetiology of rickets of prematurity. Fetal calcium accumulation during the last trimester is high. ${ }^{15}$ Pre-eclampsia which impairs placental calcium transfer ${ }^{16}$ is noted more often among mothers of preterm infants with rickets. ${ }^{17}$ Rapid postnatal growth demands a large calcium input which is not met by breast milk or most modified milk formulae. The parenteral regimen used during the period of the study provided $1-1.4 \mathrm{mmol} / \mathrm{kg}$ per 24 hours of calcium at a fluid intake of $150-200 \mathrm{ml} /$ $\mathrm{kg}$ a day. This contrasts with an intake of 1.6 $2.2 \mathrm{mmol} / \mathrm{kg}$ a day on a similar intake of a modified formulae but the latter would be incompletely absorbed..$^{15}$ Thus postnatally neither parenteral nor enteral feeding provides sufficient calcium to allow intrauterine accretion rates of calcium to be achieved. Calcium supplementation of the preterm infant has been shown to improve bone mineralisation. ${ }^{7}$

Disordered vitamin D metabolism has also been 
implicated in the development of rickets in preterm infants. Preterm infants seem unable to increase plasma 25-hydroxycholecalciferol levels until 38-42 weeks' postconceptual age despite intravenous supplementation with vitamin D. ${ }^{18}$ Thus impaired 25-hydroxylation of vitamin D may contribute to the development of rickets. Low values of 25-hydroxycholecalciferol have previously been noted in patients with cholestasis. Our cholestatic infant had a value of $2 \cdot 1 \mathrm{nmol}$ (normal 10-20 nmol) and his rickets did not respond until 1,25-dihydroxycholecalciferol was given.

It has also been considered that activation of vitamin $\mathrm{D}$ to 1,25 -dihydroxycholecalciferol in the immature kidney may be impaired and thus lead to the development of rickets. In 6 of the 7 infants in whom alkaline phosphatase activity exceeded $1000 \mathrm{U} / 1$ a decrease in alkaline phosphatase activity and radiological healing of rickets occurred only after the introduction of $1, \alpha$-hydroxycholecalciferol.

We thank Mr Rob Elton for statistical assistance, Leo Laboratories Limited for supplying 1,alphahydroxycholecalciferol, and Roche Products Limited for supplying 1,25-dihydroxycholecalciferol.

\section{References}

1 von Sydow G. A study of the development of rickets in premature infants. Acta Paediatr Scand [Suppl] 1946; 33: Supplement 2, 1-122.

2 Lewin P K, Reid M, Reilly B J, Swyer P R, Fraser D. Iatrogenic rickets in low birth weight infants. $J$ Pediatr 1971; 78: 207-10.

8 Tulloch A L. Rickets in the premature. Med J Aust 1974; i: $137-40$

4 Glasgow J F T, Thomas P S. Rachitic respiratory distress in small preterm infants. Arch Dis Child 1977; 52: 268-73.

5 Kulkarni P B, Hall R T, Rhodes P G, et al. Rickets in very low birth weight infants. J Pediatr 1980; 91 : 249-52.

- Hillman L S, Huebener D V, Haddad J G. Long term effects of low 25 -hydroxyvitamin $\mathrm{D}$ serum concentration in premature infants: a preliminary report. In: Norman A W, ed. Vitamin D: basic research and its clinical application. Berlin: de Gruyter, 1979: 331-4.

7 Steichen J J, Gratton T L, Tsang R C. Osteopenia of prematurity: the cause and possible treatment. $J$ Pediatr 1980; 96: 528-34.

8 Fishman W H. Perspectives on alkaline phosphatase isoenzymes. Am J Med 1974; 56: 617-50.

9 Morgenstern S, Kessler G, Auerbach J, Flor R V, Klein B. An automated $\rho$-nitrophenylphosphate serum alkaline phosphatase procedure for the autoanalyser. Clin Chem 1965; 11: 876-88.

10 Caffey J. Paediatric $x$-ray diagnosis, seventh edition. Vol. 2. Chicago: Year Book Medical Publishers, 1978: 1443-50.

11 Thomas P S, Glasgow J F T. Bone disease in infants with prolonged obstructive jaundice. Pediatr Radiol 1974; 2: 125-32.

12 Boissière $H$, Cagnat $R$, Poissonnier $M$, d'Angely $S$. Dystrophie ostéomalacique du prématuré. Ann Paediatr 1964; 11: 367-83.

18 Eek S, Gabrielsen L H, Halvorsen S. Prematurity and rickets. Pediatrics 1957; 20 : 63-77.

14 Malmberg N. Occurrence and significance of early periosteal proliferation in the diaphyses of premature infants. Acta Paediatr Scand 1945; 32: 626-33.

15 Shaw J C L. Evidence for defective skeletal mineralization in low birth weight infants: the absorption of calcium and fat. Pediatrics 1976; 57: 16-25.

${ }^{16}$ Khattab A K, Forfar J O. The interrelationship between calcium phosphorus and glucose levels in mother and infant in conditions commonly associated with placental insufficiency. Biol Neonate $1971 ; 18$ : 1-16.

17 Bosley A R J, Verrier-Jones E R, Campbell M J. Aetiological factors in rickets of prematurity. Arch Dis Child 1980 ; 55 : 683-6.

18 Hillman L S, Haddad J G. Perinatal vitamin D metabolism. II. Serial 25-hydroxyvitamin D concentrations in sera of term and premature infants. $J$ Pediatr 1975; 86: 928-35.

Correspondence to Dr J E Glass, Simpson Memorial Maternity Pavilion, Paediatric Department, Lauriston Place, Edinburgh EH3 9EF.

Received 6 August 1981 